\title{
Potential independent action of sigma receptor ligands through inhibition of the Kv2.1 channel
}

\author{
Xinying Liu ${ }^{1, *}$, Yingmei Fu' ${ }^{2,3, *}$, Huan Yang ${ }^{2}$, Timur Mavlyutov ${ }^{2,4}$, Jun Li ${ }^{2,5}$, Christopher \\ R. McCurdy ${ }^{6}$, Lian-Wang Guo ${ }^{2,7,8}$ and Bikash R. Pattnaik ${ }^{7,9}$ \\ ${ }^{1}$ Departments of Pediatrics, University of Wisconsin School of Medicine and Public Health, Madison, WI, USA \\ ${ }^{2}$ Department of Surgery, University of Wisconsin School of Medicine and Public Health, Madison, WI, USA \\ ${ }^{3}$ Shanghai Key Laboratory of Psychotic Disorders, Shanghai Mental Health Center, Shanghai Jiao Tong University School of \\ Medicine, Shanghai, PR China \\ ${ }^{4}$ Department of Anesthesiology, University of Wisconsin School of Medicine and Public Health, Madison, WI, USA \\ ${ }^{5}$ Department of Ophthalmology, The Third People's Hospital of Dalian, Dalian, PR China \\ ${ }^{6}$ Department of Medicinal Chemistry, College of Pharmacy, University of Florida, Gainesville, FL, USA \\ ${ }^{7}$ McPherson Eye Research Institute, University of Wisconsin, Madison, WI, USA \\ ${ }^{8}$ Department of Surgery and Department of Physiology \& Cell Biology, Davis Heart and Lung Research Institute, The Ohio \\ State University, Columbus, OH, USA \\ ${ }^{9}$ Department of Pediatrics, Department of Ophthalmology and Visual Sciences, University of Wisconsin School of Medicine \\ and Public Health, Madison, WI, USA \\ *These authors have contributed equally to this work \\ Correspondence to: Bikash R. Pattnaik, email: bikashp@pediatrics.wisc.edu
}

Lian-Wang Guo, email: Lianwang.Guo@osumc.edu

Keywords: KV2. 1 channel, CRISPR/Cas9, sigma receptor ligands, patch-clamp, electroretinogram

Received: April 21,2017 Accepted: June 16, $2017 \quad$ Published: July 26, 2017

Copyright: Liu et al. This is an open-access article distributed under the terms of the Creative Commons Attribution License 3.0 (CC BY 3.0), which permits unrestricted use, distribution, and reproduction in any medium, provided the original author and source are credited.

\section{ABSTRACT}

The sigma-1 receptor $(\sigma 1-R)$ and sigma-2 receptor $(\sigma 2-R)$ are potential drug targets for treatment of cancer, pain, depression, retinal degeneration and other neuronal diseases. Previous reports show that sigma-1 receptor modulates the activities of multiple channels. We are interested in possible sigma receptor modulation of Kv2.1, a $\mathrm{K}^{+}$channel abundant in retinal photoreceptors. We tested the effect of established sigma receptor ligands on Kv2.1 channels which were stably expressed in HEK293 cells. Surprisingly, $\sigma 1-R$ antagonists inhibited Kv2.1 currents in both wild type and $\sigma 1-R$ knockout HEK293 cells that we engineered using the CRISPR/ Cas9 technology. Moreover, PB28, a o1-R antagonist and also o2-R agonist, inhibited Kv2.1 in $\sigma 1-R$ knockout cells, but this action was not blocked by the $\sigma 2-R$ antagonists that did not have an effect on Kv2.1. We also observed inhibition of electroretinogram by PB28 in wild type as well as $\sigma 1-R$ knockout mice. Thus, the results in this study indicate that the Kv2.1-inhibiting function of the sigma ligands is not sigma receptor dependent, suggesting a direct effect of these ligands on the Kv2.1 channel.

\section{INTRODUCTION}

Sigma receptors are classified into the sigma-1 $(\sigma 1-\mathrm{R})$ and sigma-2 receptor $(\sigma 2-\mathrm{R})$ subtypes based on their distinct as well as shared ligand binding characteristics [1]. The $\sigma 1-\mathrm{R}$ is a molecular chaperone primarily residing in the endoplasmic reticulum (ER) membrane with an ability to translocate to the plasma membrane [2]. The $\sigma 2-\mathrm{R}$ has not been cloned [3]. Both $\sigma 1-\mathrm{R}$ and $\sigma 2-\mathrm{R}$ are ubiquitously distributed in mammalian tissues with high abundance in the central nervous system including the retina, implicating their 
functions in key physiological and pathophysiological processes [4]. Indeed, growing evidence indicates an important role of $\sigma 1-\mathrm{R}$ in neurodegenerative diseases $[5,6]$; pharmacological activation of $\sigma 1-\mathrm{R}$ rescues degenerate cones in the rd10 mouse model of retinitis pigmentosa [7].

$\sigma 1-\mathrm{R}$ is considered as a pluripotent modulator involved in a plethora of cellular signaling activities [8]. A great majority of $\sigma 1-\mathrm{R}$ (and all $\sigma 2-\mathrm{R}$ ) modulations were identified via pharmacology using $\sigma-\mathrm{R}$ agonists and antagonists, many of which are known to bind other targets too [9]. The best known $\sigma 1-\mathrm{R}$ function probably is its modulations of voltage-gated $\mathrm{Ca}^{2+}[10$ 13], $\mathrm{Na}^{+}$[14-16] and $\mathrm{K}^{+}$channels [17-19], via direct or indirect interactions [20]. $\sigma 1-\mathrm{R}$ inhibits the activity of several $\mathrm{K}^{+}$channels, including $\mathrm{Kv} 1.2, \mathrm{Kv} 1.3$, and Kv1.4 [18, 19, 21]; its interactions with these proteins were confirmed by co-immunoprecipitation experiments $[19,21]$.

Kv2.1 channels play an important role in neuronal systems including the neural retina [22]. The diverse functions of Kv2.1 include regulations of neuronal excitability and neural transmitter release. Recently, a prominent pro-apoptotic role of Kv2.1 in neurons has been recognized, and inhibition of Kv2.1 has shown neuroprotective effects [23]. As such, Kv2.1 is proposed to be a potential novel therapeutic target for treating neurodegenerative diseases [24] [23]. Interestingly, in our recent study using an Amyotrophic Lateral Sclerosis (ALS) mouse model, $\sigma 1-\mathrm{R}$ in motoneuron subsurface ER cisternae was found in juxtaposition with Kv2.1 in the plasma membrane, implicating possible $\sigma 1-R$ regulation of Kv2.1 activity through direct or indirect interactions [25]. In light of the reported opposite roles of $\sigma 1-\mathrm{R}$ and $\mathrm{Kv} 2.1$ in neuronal cell survival as well as their subcellular proximity in motoneurons, we hypothesized that activating $\sigma 1-\mathrm{R}$ with an agonist would have an inhibitory effect on Kv2.1 activity; this may partially account for the neuroprotective role of $\sigma 1-\mathrm{R}$ in degenerate retinas.

Therefore, in this study we set out to test the effect of established $\sigma 1-\mathrm{R}$ agonists and antagonists on Kv2.1 current in a Kv2.1 stable-expression human cell line. We were able to engineer the Kv2.1-expressing cell line to knock out $\sigma 1-R$, using the CRISPR/Cas9 genome-editing technology. This $\sigma 1-\mathrm{R}$ knockout cell line provided a powerful tool to delineate whether a $\sigma-\mathrm{R}$ ligand effect on Kv2.1 is $\sigma 1-\mathrm{R}$-specific. To our surprise, while $\sigma 1-\mathrm{R}$ agonist PRE084 showed no effect, $\sigma 1-\mathrm{R}$ antagonists BD1047 and NE100 inhibited Kv2.1 current in both $\sigma 1-\mathrm{R}$ wild type (WT) and $\sigma 1-\mathrm{R}$ knockout (KO) cells; while $\sigma 2-\mathrm{R}$ agonist PB28 potently inhibited Kv2.1, this action was not blocked by a highly $\sigma 2$-R-selective novel antagonist (CM398) [3]. These results uncovered a paradoxical $\sigma$-R-independent inhibition of Kv2.1 by selective $\sigma$-R ligands.

\section{RESULTS}

\section{$\sigma 1-R$ antagonists BD1047 and NE100 but not agonist PRE084 inhibit Kv2.1 current in Kv2.1-overexpressing HEK293 cells}

To test our hypothesis that activation of $\sigma 1-\mathrm{R}$ inhibits the Kv2.1 channel, we used a HEK293 cell line stably overexpressing the Kv2.1 protein, as HEK293 cells are characteristic of extremely low intrinsic channel activities and to our advantage, these cells express sigma receptors [26]. Kv2.1 current was measured after the application of highly $\sigma 1-R$-selective agonist PRE084 [27]. We found that treatment of cells with $10 \mu \mathrm{M}$ of PRE084 had no effect on $\mathrm{Kv} 2.1$ current amplitudes measured as a voltage pulse to $+50 \mathrm{mV}$ from a holding potential of $-60 \mathrm{mV}$ (Figure 1A). However, upon treatment of Kv2.1-expressing cells with a commonly used $\sigma 1-\mathrm{R}$ antagonist $\mathrm{BD} 1047(50 \mu \mathrm{M})$ [27], we noticed that the current amplitude was severely reduced (Figure 1B). We then used another established high-affinity $\sigma 1-\mathrm{R}$ antagonist, NE100 $(50 \mu \mathrm{M})[9,27]$, to verify the BD1047-induced effect. We found that NE100 also reduced current amplitude (Figure 1C).

Time course of drug effect on Kv2.1 current at $+50 \mathrm{mV}$ is shown in Figure 1D, 1E, and 1F. Five minute application of Pre84, did not show any rundown of the outward current (Figure 1D). The reduction in the current during the application of BD1047 was quick (inhibition time constant $34.45 \mathrm{sec}$ ) and reversible (Figure 1E). NE100 inhibition of Kv2.1 current was rapid (inhibition time constant of $21 \mathrm{sec}$ ) and reversible (Figure 1F) during the six minute experiment. Average response of the three drugs on Kv2.1 is presented as current-voltage (I-V) plot comparison. Pre84 did not change Kv2.1 I-V plot (Figure $1 \mathrm{G})$. In response to a $+50 \mathrm{mV}$ voltage pulse, Kv2.1 current density measured $152 \pm 22 \mathrm{pA} / \mathrm{pF}$ that was only reduced to $143 \pm 21 \mathrm{pA} / \mathrm{pF}(\mathrm{P}<0.5)$ after treatment with PRE084. The I-V plot showed that BD1047 inhibited outward current only (Figure $1 \mathrm{H}$ ). Average current density at +50 $\mathrm{mV}$ was reduced from $135 \pm 9 \mathrm{pA} / \mathrm{pF}$ to $67 \pm 15 \mathrm{pA} /$ pF $(60 \%$ inhibition, $\mathrm{P}<0.05)$. Similarly, we observed a significant reduction in the outward current by NE100 on comparing the I-V relationship (Figure 1I). Average current density measured at $+50 \mathrm{mV}$ were $149 \pm 17 \mathrm{pA} /$ $\mathrm{pF}$ in control solution compared to $77 \pm 13 \mathrm{pA} / \mathrm{pF}$ in the presence of NE100 $(\mathrm{P}<0.05)$ indicating $50 \%$ inhibition of $\mathrm{Kv} 2.1$ channel current.

We wondered if these inhibitors had any role in voltage dependent activation or gating of Kv2.1 channel. The plot of steady-state voltage activation showed a clear saturation within the membrane voltage range and an inhibition of outward conductance between -20 and $-60 \mathrm{mV}$ by both BD1047 and NE100 (Figure 1J). The half-activation voltage of control Kv2.1 channel (without ligand treatment) was $6 \pm 0.38 \mathrm{mV}$. This was not significantly different from $4 \pm 1.75 \mathrm{mV}$ for BD1047 
A

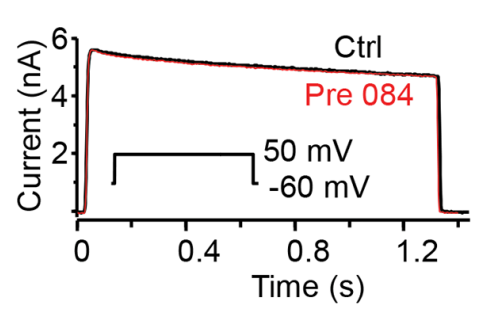

D

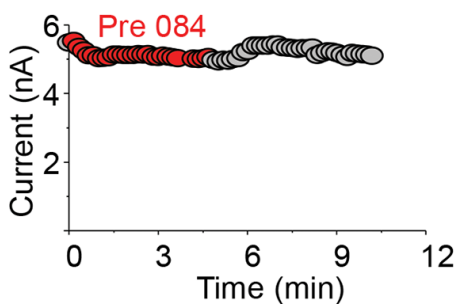

B

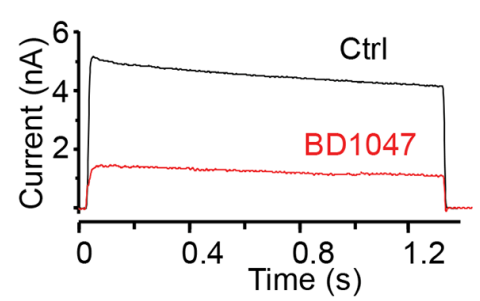

E

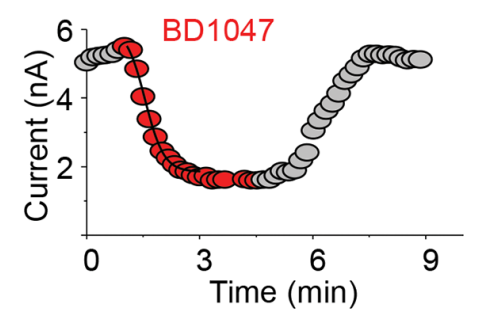

C

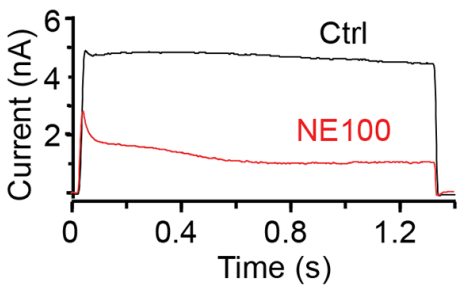

F

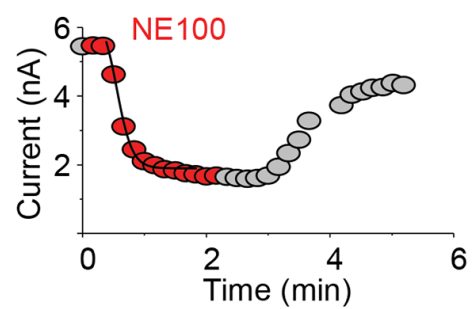

G

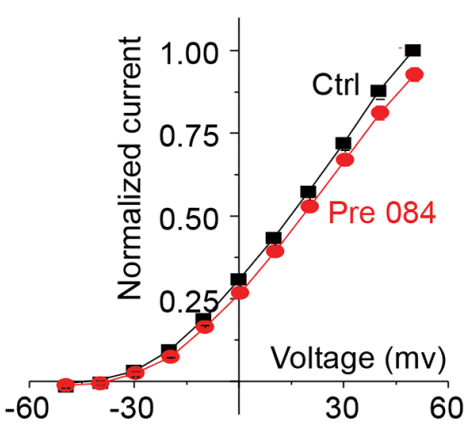

$\mathrm{H}$

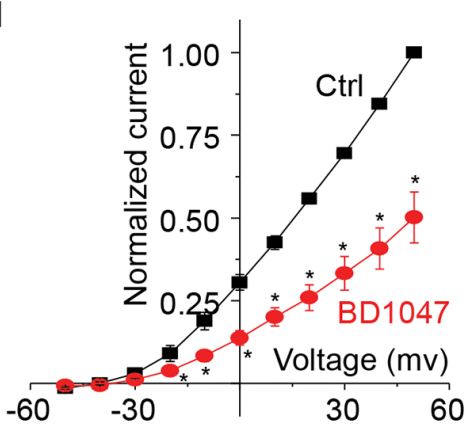

I

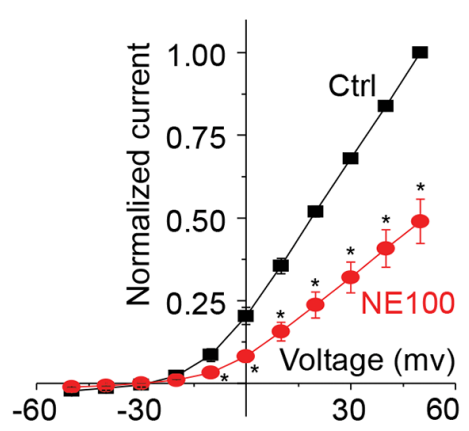

J

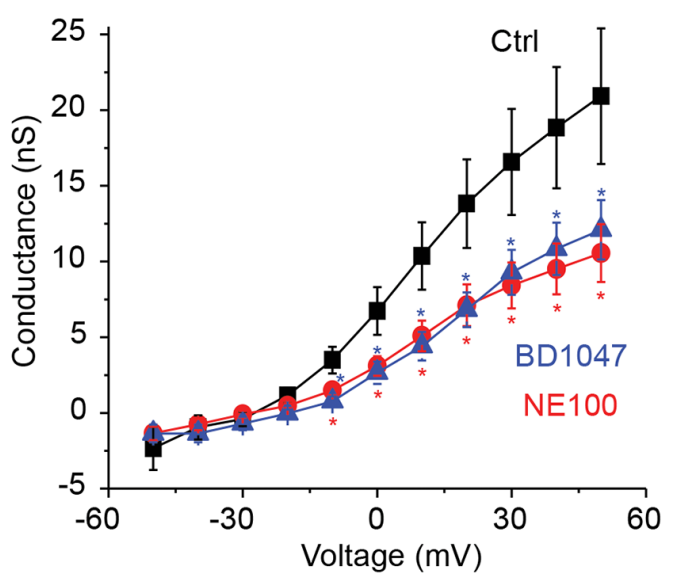

K

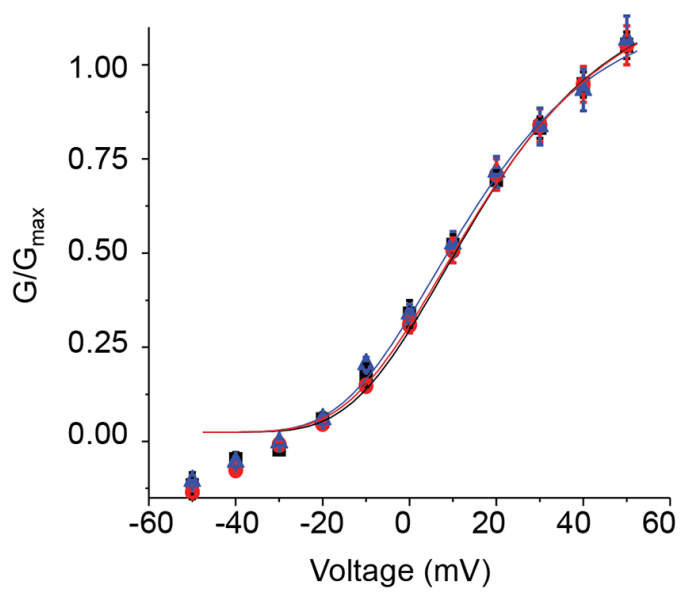

Figure 1: Only s1-R antagonists inhibit Kv2.1 channel current. (A) Representative current traces from a cell expressing Kv2.1 channel before (HR; black trace) and during treatment with $\sigma 1-\mathrm{R}$ receptor agonist PRE084 $(10 \mu \mathrm{M}$, red trace). Inset voltage pulse to 50 $\mathrm{mV}$ from a holding potential of $-60 \mathrm{mV}$. (B) Representative Kv2.1 channel current traces from a cell treated with $\sigma 1-\mathrm{R}$ antagonist BD1047 (50 $\mu \mathrm{M}$, red trace) compared to total current (black trace). (C) Comparison of Kv2.1 current traces before (HR, black trace) and during treatment with $\sigma 1-\mathrm{R}$ antagonist NE100 (50 $\mu \mathrm{M}$, red trace). (D) Time course of current amplitude at $+60 \mathrm{mV}$. Recordings during Pre84 treatment is represented as red filled circles. (E) Filled circles (red) showing current amplitude time course during treatment of Kv2.1 expressing cells with BD1047. (F) Kv2.1 outward current amplitude as in D in presence of NE100 (50 $\mu \mathrm{M}$, red filled circles). Both in E and F the solid line represents single exponential curve fit. (G) Average Kv2.1 whole-cell normalized current-voltage plot obtained in control solution (black squares) and during application of Pre084. (H) Comparison of average normalized current-voltage curve in presence of control bath solution and BD1047. (I) Average normalized current-voltage curve determined in control solution (black squares) and NE100 (red circles). (J) The G-V relationships of the control (solid black square), and in presence of BD1047 (blue triangle) or NE100 (red circle) are illustrated. (K) Normalized G-V curves as in J were fitted with the Boltzmann function. Data points in G-K are mean \pm SEM (n=5). * $\mathrm{P}<0.05$ compared to control. 
and $6 \pm 1.05 \mathrm{mV}$ for NE100 treatment $(\mathrm{P}<0.5)$. There was no change either in slope conductance between the three conditions (Figure 1K). Taken together, our results conclude that the two $\sigma 1-\mathrm{R}$ antagonists but not agonist PRE084 are able to inhibit the Kv2.1 channel.

\section{Knockout of $\sigma 1-\mathrm{R}$ does not affect the Kv2.1 inhibitory effect of BD1047 and NE100}

To investigate whether this Kv2.1 inhibition by $\sigma 1-\mathrm{R}$ antagonists was truly mediated by $\sigma 1-\mathrm{R}$, we used the CRISPR/Cas9 technology to specifically knock out the $\sigma 1-\mathrm{R}$ protein in Kv2.1-overexpressing HEK293 cells. As indicated by Western blotting (Figure 2A), o1-R knockout was complete when using gRNAs \#1 and \#3 but not \#2, and Kv2.1 protein levels were not altered after $\sigma 1-\mathrm{R}$ depletion. We chose gRNA\#1 to produce $\sigma 1-\mathrm{R}$ KO cells for experiments throughout this study.

We then tested the effect of $\sigma 1-\mathrm{R}$ antagonists on Kv2.1 current in $\sigma 1-\mathrm{R} \mathrm{KO}$ (and Kv2.1-overexpressing) HEK293 cells. As illustrated in Figure 2B, BD1047 inhibited outward current between -20 to $+50 \mathrm{mV}$. In response to $\mathrm{BD} 1047$, outward current at $+50 \mathrm{mV}$ membrane potential was reduced from $135 \pm 9 \mathrm{pA} / \mathrm{pF}$ to $67 \pm 15 \mathrm{pA} / \mathrm{pF}(\mathrm{P}<0.05, \mathrm{n}=5)$. Similarly, $\sigma 1-\mathrm{R}$ antagonist NE100 inhibited Kv2.1 outward current between -30 to $+50 \mathrm{mV}$ as shown in Figure 2C. In 6 cells, NE100 inhibited $50 \%$ of Kv2.1 current at $+50 \mathrm{mV}$ membrane potential, which was reduced from $118 \pm 9$ to $56 \pm 12$ $\mathrm{pA} / \mathrm{pF}(\mathrm{P}<0.05, \mathrm{n}=6)$. Similar to the observation with o1-R WT cells (Figure 1), inhibition of Kv2.1 current in $\sigma 1-\mathrm{R}$ KO cells occurred within seconds after application of ligands (not shown). These results suggest that the inhibition of Kv2.1 current by $\sigma 1-\mathrm{R}$ antagonists NE100 and BD1047 is $\sigma 1-\mathrm{R}$ independent.

\section{б2-R agonist PB28 potently inhibits Kv2.1 current in both $\sigma 1-\mathrm{R}$ WT and $\sigma 1-\mathrm{R}$ KO cells}

Although BD1047 and NE100 are deemed $\sigma 1-\mathrm{R}$ selective ligands, they also bind $\sigma 2-\mathrm{R}$ albeit with $\sim 40$ fold lower affinities [9]. Thus, an interesting question arose as to whether the observed inhibition of the Kv2.1 channel was actually mediated by $\sigma 2-\mathrm{R}$. Our $\sigma 1-\mathrm{R} \mathrm{KO}$ HEK293 cells provided a unique opportunity to address the role of $\sigma 2-\mathrm{R}$ because the binding of a $\sigma 2-\mathrm{R}$ ligand to $\sigma 1-\mathrm{R}$ was ruled out. We opted to use a well-established high-affinity $\sigma 2-\mathrm{R}$ agonist (PB28) for investigation [28]. PB28 is also a high-affinity $\sigma 1-\mathrm{R}$ antagonist thus ideally representing $\sigma$-R ligands shared by the $\sigma 1-\mathrm{R}$ and $\sigma 2-\mathrm{R}$ subtypes [28]. In Figure 3, we show the effect of PB28 on Kv2.1 current in the $\sigma 1-\mathrm{R}$ KO HEK293 cells. We noticed a progressive decrease in outward current following PB28 application, and the inhibition of Kv2.1 current was PB28 concentration dependent (data not shown). Since $10 \mu \mathrm{M}$ PB28 (Figure 3A, red circle) nearly abolished Kv2.1 outward current as measured at $+50 \mathrm{mV}$, we chose this concentration for later experiments. Although PB28 binds to $\sigma 1-\mathrm{R}$ and $\sigma 2-\mathrm{R}$ with a $\mathrm{Kd}$ (or $\mathrm{Ki}$ ) in the sub-nanomolar range, the affinities were determined with membranes isolated from lysed cells. In studies using intact cells, PB28 concentrations ranging from 5-50 $\mu \mathrm{M}$ have been commonly used [29]. The time course of Kv2.1 current inhibition by $10 \mu \mathrm{M}$ PB28 is shown in Figure $3 \mathrm{~A}$. The inhibition was quick (inhibition time constant of $22 \mathrm{sec}$ ) and completely reversible. The average plot of the I-V curve (Figure 3B) also showed outward current inhibition between -30 to $+50 \mathrm{mV}$. The Kv2.1 current of $132 \pm 3$ $\mathrm{pA} / \mathrm{pF}$ measured at $+50 \mathrm{mV}$ membrane potential was reduced to $47 \pm 10 \mathrm{pA} / \mathrm{pF}$ in the presence of $10 \mu \mathrm{M} \mathrm{PB} 28$, indicating a $65 \%$ inhibition of current $(\mathrm{P}<0.005, \mathrm{n}=6)$.
A

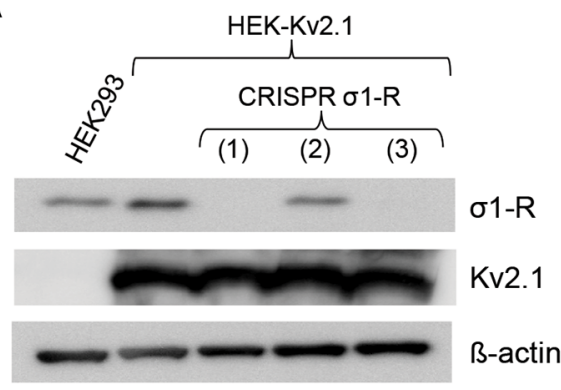

B

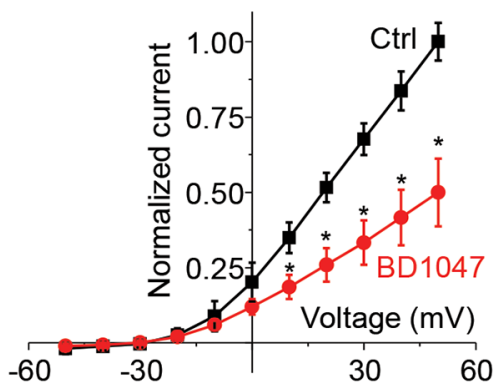

C

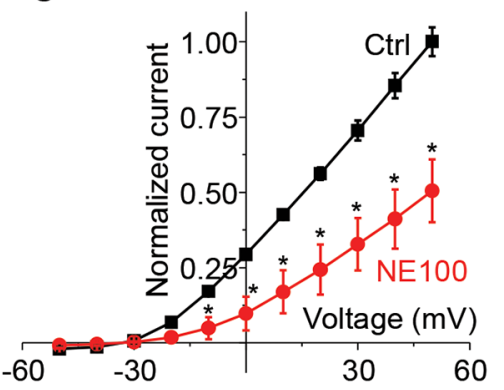

Figure 2: Antagonists inhibits Kv2.1 current after CRISPR/Cas9 mediated $\sigma 1-R$ receptor knockout. (A) Western blot confirmed protein levels for $\sigma 1-\mathrm{R}, \mathrm{Kv} 2.1$, and B-actin. Lane 1 represents HEK293 cells and lanes 2-5 represent HEK-Kv2.1 cells. Three CRISPR/Cas9 mediated $\sigma 1-\mathrm{R}$ KO cell samples are marked as 1, 2, and 3. (B) Normalized current-voltage curve before (black squares) and after (red circles) treatment of cells, as in lane 3(A), with BD1047. (C) Normalized current-voltage curve for no drug control and with 50 $\mathrm{M} N E 100$. Data points in $\mathrm{B}$ and $\mathrm{C}$ are mean $\pm \mathrm{SE}$ of the mean from at least 5 independent recordings and $* \mathrm{P}<0.05$. 
A
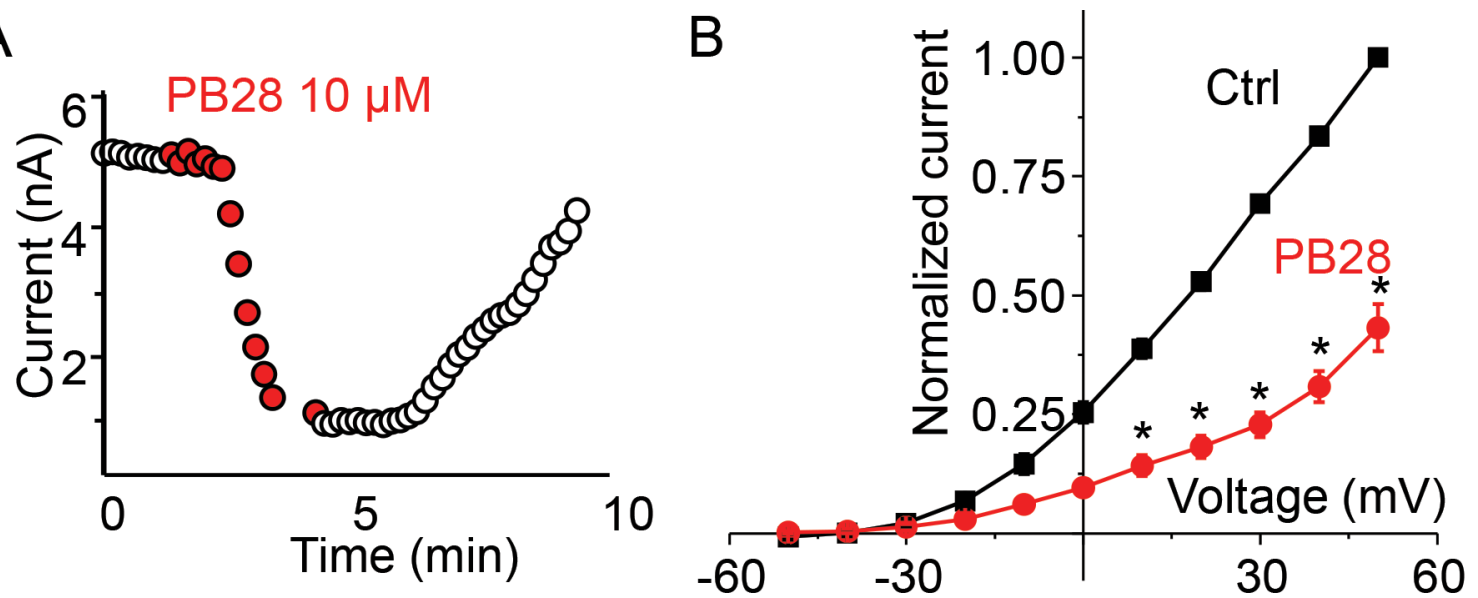

C
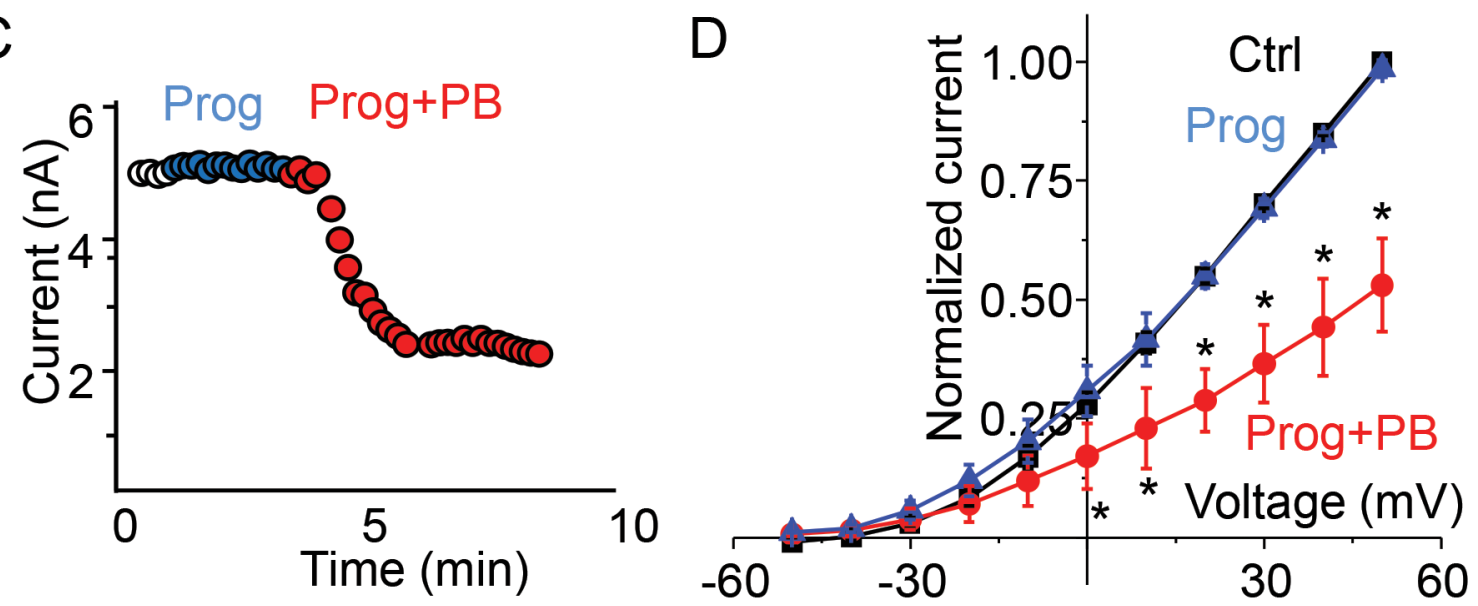

E
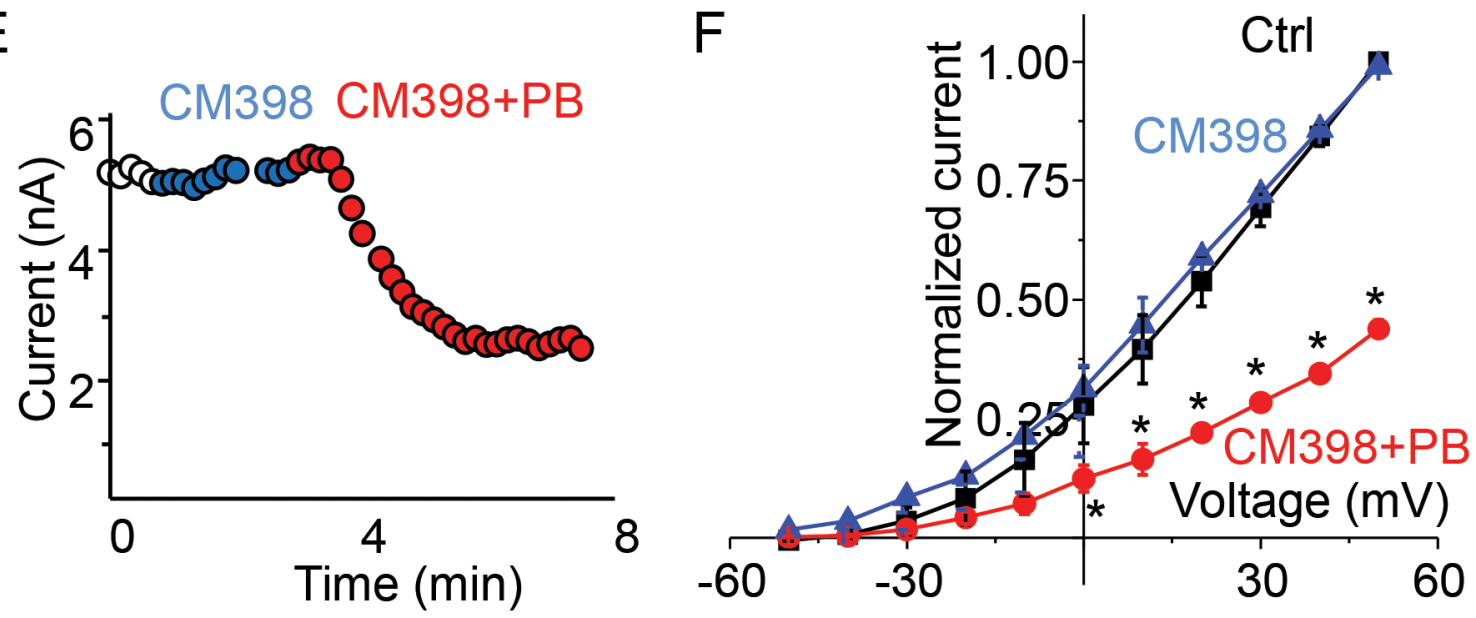

Figure 3: $\sigma 2-\mathrm{R}$ agonist PB28 but not antagonists inhibits Kv2.1 current in $\sigma 1-\mathrm{R}$ knockout HEK 293 cells expressing Kv2.1 channel. (A) Representative cell showing current amplitude time course over 10 minutes with duration of PB28 application shown as red circles. (B) A plot of average normalized current-voltage curve in control (black trace) and after PB28 treatment (red trace). (C) Time course of current amplitude for a cell during the treatment of progesterone $20 \mu \mathrm{M}$ (blue circles) or during the treatment of progesterone $10 \mu \mathrm{M}$ and PB28 $10 \mu \mathrm{M}$ (red circles). (D) Average normalized current-voltage plot showing the effect of progesterone (blue trace) and progesterone plus PB28 (red trace) on Kv2.1 current. (E) In a representative cell current amplitude time course during the application of CM398 $20 \mu \mathrm{M}$ alone (blue circle) or CM398 $10 \mu \mathrm{M}$ plus PB28 $10 \mu \mathrm{M}$ (red circle). (F) Average plot of normalized current-voltage plot comparing Kv2.1 channel current responses to CM398 (blue trace) of CM398 plus PB28 (red trace) treatment. 


\section{Inhibition of Kv2.1 by $\sigma 2-\mathrm{R}$ agonist $\mathrm{PB} 28$ is not blocked by $\sigma 2-R$ antagonists}

We then measured the effect of two $\sigma 2-R$ antagonists, progesterone and CM398, on Kv2.1 current in $\sigma 1-\mathrm{R}$ KO HEK293 cells. As illustrated in Figure 3C, progesterone at $20 \mu \mathrm{M}$ had no effect on Kv2.1 current amplitude during more than 2 minutes of application (Figure 3C blue circles). Addition of PB28 $(10 \mu \mathrm{M})$ together with progesterone $(10 \mu \mathrm{M})$ still rapidly inhibited Kv2.1 current (Figure 3C red circles). Figure 3D further summarizes our findings that progesterone had no effect on Kv2.1 current voltage curve (Figure 3D, blue triangle), and PB28 inhibited outward current between -30 to $+50 \mathrm{mV}$ regardless of the presence of progesterone (Figure 3D, red circles). Current amplitude at $+50 \mathrm{mV}$ membrane potential measured to be $133 \pm 11 \mathrm{pA} / \mathrm{pF}$ for control (no ligand), $132 \pm 12 \mathrm{pA} / \mathrm{pF}(\mathrm{P}<0.5, \mathrm{n}=4)$ for progesterone, and $61 \pm 8 \mathrm{pA} / \mathrm{pF}(\mathrm{P}<0.005, \mathrm{n}=4)$ for PB28 plus progesterone treatment. A novel highly $\sigma 2-\mathrm{R}-$ selective antagonist (>1000 fold over $\sigma 1-R)$, CM398 (20 $\mu \mathrm{M}$ ) [3], had no effect on Kv2.1 current either (Figure $3 \mathrm{E}$, blue circle) during approximately 2 minutes of drug application. Subsequent addition of PB28 $(10 \mu \mathrm{M})$ and CM398 $(10 \mu \mathrm{M})$ reduced the current amplitude (Figure $3 \mathrm{E}$, red circles). On an average, current-voltage plot showed no effect of CM398 on PB28 inhibition of Kv2.1 outward current (Figure 3F). At $+50 \mathrm{mV}$ the amplitudes measured $143 \pm 7 \mathrm{pA} / \mathrm{pF}$ for control, $144 \pm 9 \mathrm{pA} / \mathrm{pF}$ for CM398 $(\mathrm{P}<0.5, \mathrm{n}=3)$, and $55 \pm 11$ for PB28 and CM398 $(\mathrm{P}<0.05, \mathrm{n}=3)$. These results support an assertion that both $\sigma 2-\mathrm{R}$ antagonists progesterone and CM398 do not block the Kv2.1-inhibiting action of $\sigma 2-\mathrm{R}$ agonist PB28, indicative of a $\sigma 2$-R-independent effect.

The results from our experiments using various $\sigma-\mathrm{R}$ ligands are summarized in Figure 4. While $\sigma 1-\mathrm{R}$ agonist PRE084 did not inhibit the Kv2.1 channel, $\sigma 1-\mathrm{R}$ antagonists BD1047, NE100, and PB28 each inhibited Kv2.1 current to similar degrees in $\sigma 1-\mathrm{R}$ WT and $\mathrm{KO}$ cells. $\sigma 2-\mathrm{R}$ agonists PB28 and SM21 potently inhibited Kv2.1 in both WT and KO cells, but the PB28 inhibitory effect could not be blocked by $\sigma 2-\mathrm{R}$ antagonists progesterone and CM398. Whereas progesterone and CM398 did not show an inhibitory effect, another $\sigma 2-\mathrm{R}$ antagonist, CM777 [3], strongly inhibited Kv2.1 activity. On the other hand, DTG as a classic sigma receptor ligand that binds to both $\sigma 1-\mathrm{R}$ and $\sigma 2-\mathrm{R}$ (affinities: $\sim 50 \mathrm{nM}$ ) did not inhibit Kv2.1 even at $50 \mu \mathrm{M}$ (data not shown). These results together indicate that those Kv2.1-inhibiting $\sigma-\mathrm{R}$ ligands acted independently of $\sigma 1-\mathrm{R}$ and $\sigma 2-\mathrm{R}$.

\section{PB28 reduces ERG a-wave and b-wave amplitudes in $\sigma 1-R$ WT and KO cells}

The Kv2.1 channel is highly expressed in retinal photoreceptor cells although its functions in mammalian retinas are not well understood $[22,30]$. Consistently, our immunostaining data show that $\mathrm{Kv} 2.1$ is predominantly localized in the photoreceptor inner segment (Figure 5A, red staining) with minor amounts in other retinal layers. In contrast, while present in all retinal layers, $\sigma 1-\mathrm{R}$ is more abundant in the ganglion cell layer (Figure 5A, green staining), as also observed previously in our and other's studies [31, 32]. As shown on the magnified images of two ganglion cells (Figure 5A lower panel), although Kv2.1 in the plasma membrane was in proximity to $\sigma 1-\mathrm{R}$ in the ER, there was no appreciable overlap of immunostained $\mathrm{Kv} 2.1$ and $\sigma 1-\mathrm{R}$.

Because of the abundance of the Kv2.1 channel in photoreceptors in the mouse retina and its inhibition by PB28 in vitro, we explored a possible impact of PB28 on electroretinogram (ERG) in vivo. We first determined the effect of PB28 on ERG in WT mice, via intravitreal injection of PB28 into one eye and vehicle control (equal amount of DMSO in PBS) into the contralateral eye. Figure 5B shows scotopic ERG amplitudes of aand b-waves after administration of PB28 or vehicle, which were elevated in response to increasing light flash stimulus, indicating retinal responses induced specifically by light. Interestingly, compared to vehicle control (a-wave, black; b-wave, red; Figure 5B), PB28 substantially reduced average a-wave (Figure 5B, blue) and b-wave (Figure $5 \mathrm{~B}$, purple) amplitudes by $\sim 50 \%$.

Considering reported $\sigma 1-\mathrm{R}$ modulations of various channels; $\mathrm{Ca}^{2+}$ [10-13], $\mathrm{Na}^{+}$[14-16] and $\mathrm{K}^{+}$channels [17-19], some present in the retina, we performed the same ERG experiments also in $\sigma 1-\mathrm{R} \mathrm{KO}$ mice to assess whether $\sigma 1-\mathrm{R}$ is possibly involved in the PB28-induced ERG inhibition. As indicated in Figure 5C, PB28 also inhibited a-waves in $\sigma 1-\mathrm{R} \mathrm{KO}$ mice (Figure $5 \mathrm{C}$, blue vs black) albeit to a less degree relative to an $\sim 50 \%$ inhibition in WT mice (Figure 5B). This difference between $\sigma 1-\mathrm{R}$ $\mathrm{KO}$ and WT suggests a partial involvement of $\sigma 1-\mathrm{R}$ in PB28-induced a-wave attenuation. However, like in WT mice, $b$-wave amplitudes were still substantially reduced by $\sim 50 \%$ after PB28 injection in $\sigma 1-\mathrm{R} \mathrm{KO}$ mice (Figure $5 \mathrm{C}$, purple vs red), demonstrating a strong non- $\sigma 1-\mathrm{R}$ effect. In addition, while the basal levels (no PB28) of a-waves were slightly lower in $\sigma 1-\mathrm{R} \mathrm{KO}$ versus WT mice, $\mathrm{b}$-waves were markedly smaller in $\sigma 1-\mathrm{R} \mathrm{KO}$ mice (highest at $150 \mu \mathrm{V} v s 220 \mu \mathrm{V}$ compared to WT, in Figure 5C and $5 \mathrm{~B}$, respectively, red curves).

These results suggest that PB28 inhibition of mouse ERG in vivo is partly $\sigma 1-\mathrm{R}$ associated, and also by mechanisms independent of $\sigma 1-R$, which possibly involves Kv2.1.

\section{DISCUSSION}

We made an unexpected finding that a defined group of $\sigma$-R-selective ligands potently inhibit Kv2.1 currents paradoxically in an $\sigma$-R-independent manner. Both $\sigma$-Rs 
A

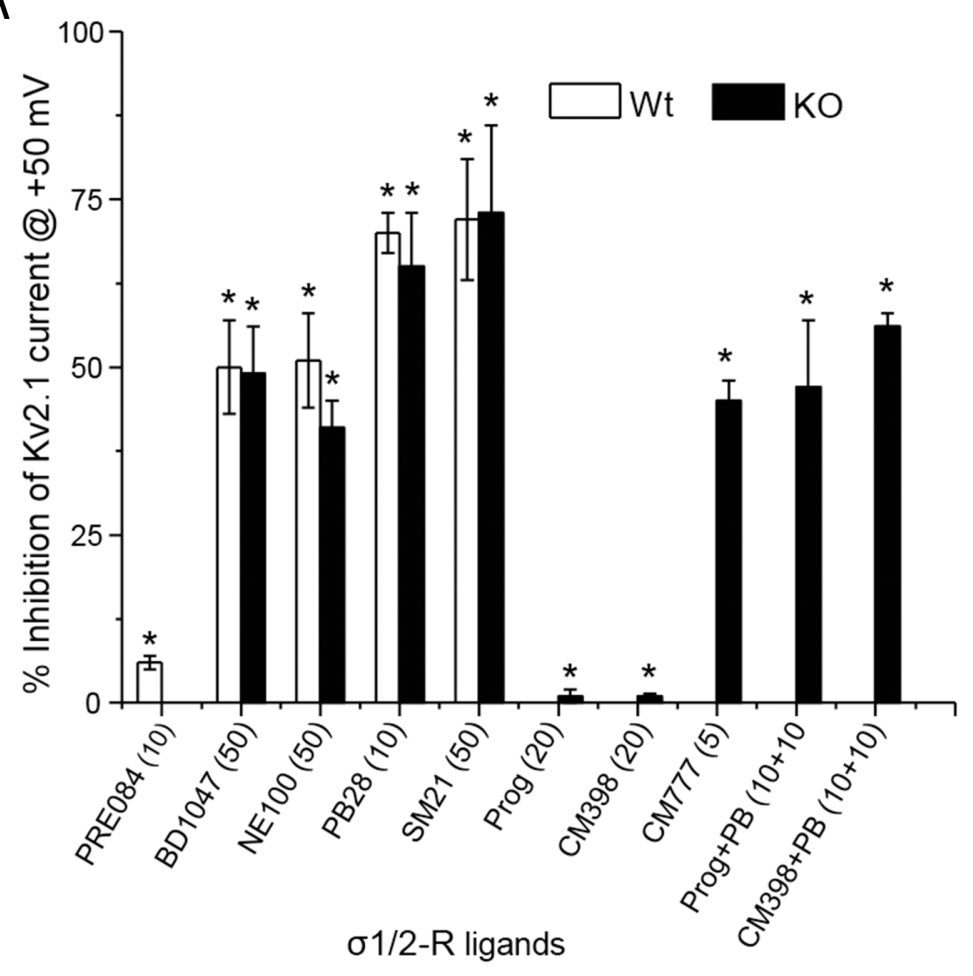

B

\begin{tabular}{|c|c|c|c|c|}
\hline \multirow[b]{2}{*}{ Ligand } & \multicolumn{2}{|c|}{ Affinity $(\mathrm{nM})$} & \multirow{2}{*}{$\begin{array}{l}\text { Agonist or } \\
\text { Antagonist }\end{array}$} & \multirow[t]{2}{*}{ Chemical Structure } \\
\hline & $\sigma 1-R$ & $\sigma 2-R$ & & \\
\hline PRE084 [44] & 2.2 & 13091 & $\begin{array}{l}\text { o1-R } \\
\text { Agonist }\end{array}$ & \\
\hline BD1047 [9] & $0.93 \pm 0.14$ & $47 \pm 0.6$ & $\begin{array}{l}\sigma 1-R \\
\text { Antagonist }\end{array}$ & \\
\hline NE100 [9] & $2.8 \pm 0.5$ & $95.5 \pm 1.0$ & $\begin{array}{l}\sigma 1-R \\
\text { Antagonist }\end{array}$ & \\
\hline PB28 [28] & 13 & 0.28 & 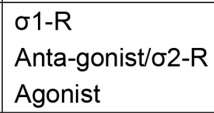 & \\
\hline CM777 [9] & $752.4 \pm 51.4$ & $0.66 \pm 0.01$ & $\begin{array}{l}\sigma 2-\mathrm{R} \\
\text { Antagonist }\end{array}$ & \\
\hline СM398 [9] & $560.4 \pm 8.7$ & $0.43 \pm 0.02$ & $\begin{array}{l}\sigma 2-R \\
\text { Antagonist }\end{array}$ & \\
\hline SM21 [45] & $>1000$ & $67.5 \pm 8.0$ & $\begin{array}{l}\sigma 2-R \\
\text { Antagonist }\end{array}$ & \\
\hline Progesterone [16] & 441 & 239 & $\begin{array}{l}\sigma 1 / 2-R \\
\text { Antagonist }\end{array}$ & \\
\hline
\end{tabular}

Figure 4: Summary of $\sigma 1$ and 2-R ligands inhibition of Kv2.1 current. (A) Bar graph summary of average \% inhibition of Kv2.1 channel in HEK293 cells (open bar) or after $\sigma 1-\mathrm{R}$ knockout (black bar) in HEK 293 cells in presence of various $\sigma 1-$ and $\sigma 2-\mathrm{R}$ ligands. Data is mean $\pm \operatorname{SEM}(\mathrm{n}=4$ at least) and $* \mathrm{P}<0.05$. Concentrations of the ligands are presented in the parentheses under the bar graph. (B) $\sigma 1-\mathrm{R}$ and $\sigma 2-\mathrm{R}$ binding affinities, functions, and chemical structures of $\sigma 1-\mathrm{R}$ ligands. 
and Kv2.1 are broadly distributed with diverse functions, especially in neuronal systems. Prompted by known $\sigma 1-\mathrm{R} /$ channel interactions [20] and $\sigma 1-\mathrm{R}$ juxtaposition with Kv2.1 [25], we initially sought to test a possible $\sigma 1-\mathrm{R}$ modulation of Kv2.1 activity. Surprisingly, our data revealed that a few high-affinity $\sigma-\mathrm{R}$ ligands inhibited Kv2.1 regardless of $\sigma-R$ activity. Although some $\sigma-R$ ligands have been reported to bind other proteins as well [9], little is known about ion channels as alternative targets of highly $\sigma$-R-selective ligands. Our findings may thus open new perspectives in pharmacological manipulations involving $\sigma-\mathrm{Rs}$ and/or the Kv2.1 channel, both emerging intervention targets.

As revealed by a series of unexpected results, the observed Kv2.1-inhibiting effect of $\sigma$-R ligands was independent of both $\sigma 1-\mathrm{R}$ and $\sigma 2-\mathrm{R}$. The first surprise was that $\sigma 1-R$ agonist PRE084 had no effect on Kv2.1 currents, in contrast to widely reported $\sigma 1-\mathrm{R}$ modulations of various channels, including Kv members [20]. Instead, we found that $\sigma 1-\mathrm{R}$ antagonists BD1047 and NE100 strongly inhibited Kv2.1 activity. Surprisingly, in $\sigma 1-\mathrm{R} \mathrm{KO}$ cells they inhibited Kv2.1 current to the same extent as in $\sigma 1-\mathrm{R}$ WT cells. This result precludes a functional involvement

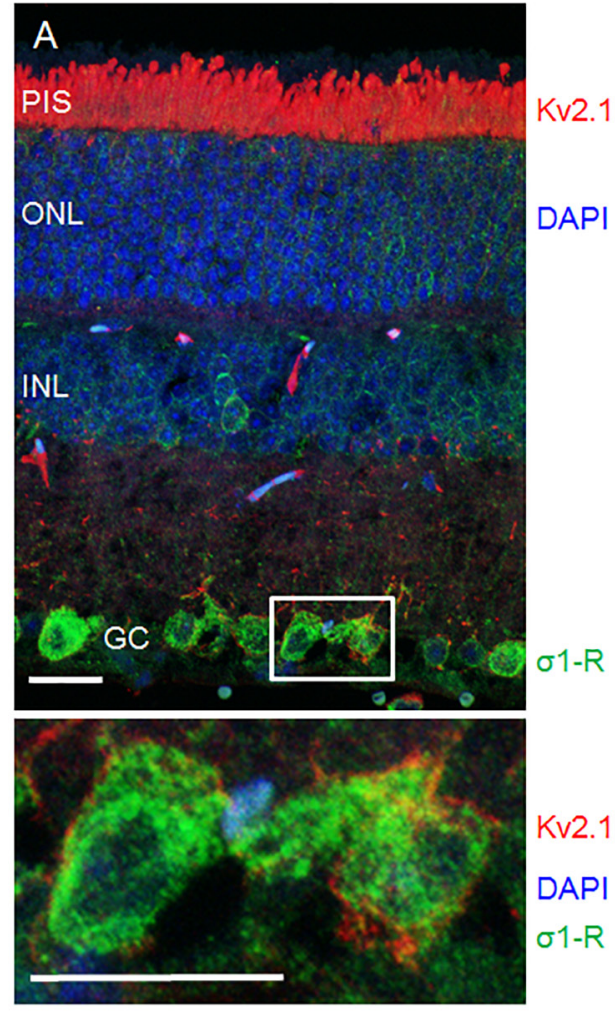

of $\sigma 1-\mathrm{R}$. Further; we found that high-affinity $\sigma 2-\mathrm{R}$ agonist (and also $\sigma 1-\mathrm{R}$ antagonist) PB28 abolished Kv2.1 function in $\sigma 1-\mathrm{R}$ WT as well as $\sigma 1-\mathrm{R} \mathrm{KO}$ cells, implicating a $\sigma 2-$ $\mathrm{R}$-related mechanism. However, neither progesterone nor CM398, both $\sigma 2-\mathrm{R}$ antagonists [9], were able to block the PB28 inhibition of Kv2.1 current, indicating that the PB28 action is a non- $\sigma 2-\mathrm{R}$ effect. On the other hand, other two structurally distinct $\sigma 2-\mathrm{R}$ antagonists (CM777 and SM21) showed Kv2.1-inhibitory potency [9]. However, the result that high-affinity $\sigma 2-\mathrm{R}$ agonist PB28 and antagonist CM777 both potently inhibit Kv2.1 strongly argues against a $\sigma 2-\mathrm{R}$-specific effect of these two $\sigma 2-\mathrm{R}$ ligands. Moreover, DTG as both a $\sigma 1-\mathrm{R}$ and a $\sigma 2-\mathrm{R}$ ligand without known off-targets did not inhibit Kv2.1 at $50 \mu \mathrm{M}$ (data not shown). Therefore, our results are compelling in supporting a $\sigma$-R-independent Kv2.1-inhibiting function of the previously deemed " $\sigma$-R-selective" ligands.

An alternative explanation would be that these Kv2.1-inhibiting ligands inhibit Kv2.1 indirectly via a $\sigma \mathrm{R} / \mathrm{Kv} 2.1$ interaction, but the $\sigma \mathrm{R}$-mediated effect is "masked" by overexpressed Kv2.1 protein. If a $\sigma \mathrm{R} / \mathrm{Kv} 2.1$ interaction were true, overexpression of Kv2.1 would greatly increase $\sigma \mathrm{R} / \mathrm{Kv} 2.1$ contacts, and a difference
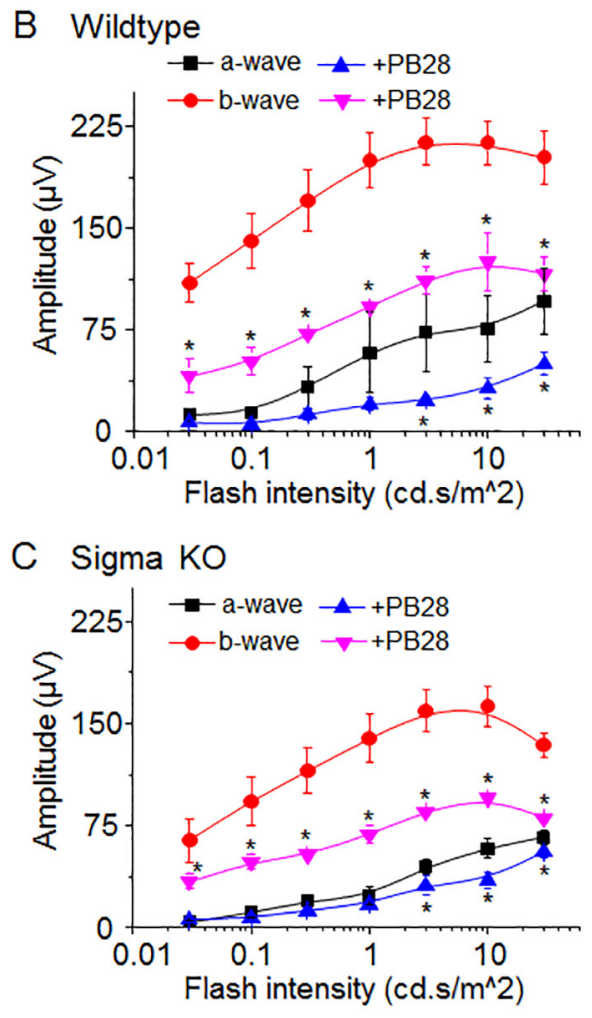

Figure 5: $\sigma$-R ligand PB28 attenuate mouse ERG possibly through Kv2.1 inhibition. (A) Micrograph of mouse retina showing localization of Kv2.1 (red) and $\sigma 1-\mathrm{R}$ (green). Nuclear layer is shown as blue DAPI staining. In the lower panel two enlarged ganglion cells marked with a white box showing Kv2.1 (red) and $\sigma 1-\mathrm{R}$ (green) immunostaining. Scale bar $15 \mu \mathrm{M}$. (B) Average response of a- and b-wave amplitude in relation to light flash intensity. Vehicle injected eye response is shown as black (a-wave) and red (b-wave) traces. PB28 injected eye is shown as blue (a-wave) and purple (b-wave) traces. (C) Average ERG a- and b-wave responses from $\sigma 1-\mathrm{R}$ knock out mice after saline or PB28 injection. Color representation as in B. Data is represented as mean \pm SEM from at least 5 observations for each point and $* \mathrm{P}<0.05$ defines significance compared to control. 
made by $\sigma 1-\mathrm{R}$ depletion would be amplified. However, we did not observe a difference in $\sigma 1-\mathrm{R}$ ligand-induced Kv2.1 inhibitory effects between $\sigma 1-\mathrm{R}$ WT and $\sigma 1-\mathrm{R}$ $\mathrm{KO}$ cells, thus a functional $\sigma 1 \mathrm{R} / \mathrm{Kv} 2.1$ association was ruled out. In support of the lack of $\sigma 1-\mathrm{R} / \mathrm{Kv} 2.1$ proteinprotein interaction, in a recent study, $\sigma 1-\mathrm{R}$ co-immunoprecipitated with Kv1.2 but not Kv2.1 in the mouse brain tissue [21]. Moreover, our immunostaining images did not show evident co-localization between Kv2.1, a plasma membrane protein, and $\sigma 1-\mathrm{R}$, an ER resident [2]. Another scenario is that $\sigma-\mathrm{R}$ ligands bind to other ion channels (e.g., $\mathrm{Ca}^{2+}, \mathrm{Na}^{+}$) which indirectly influence Kv2.1 current. Although we cannot rule out this possibility definitively, inhibition of Kv2.1 current occurred rapidly (within 40s after ligand application), which may be most reasonably explained by ligand binding directly to the Kv2.1 protein. Moreover, in support of a Kv2.1-selective effect of the $\sigma$-R ligands, we used a Kv2.1 stable-overexpression HEK293 cell line, which features extremely low abundance of other ion channels [33]. Of note, a histamine- and serotoninreceptor antagonist, cyproheptadine, was recently shown to bind $\sigma 1-\mathrm{R}$ and enhance outward $\mathrm{K}^{+}$current mediated by the Kv2.1 $\alpha$ subunit [34]. Since cyproheptadine differs drastically from the Kv2.1-inhibiting ligands studied here, it is not clear whether it interacts with Kv2.1. Nevertheless, to prove or disprove direct binding of $\sigma-\mathrm{R}$ ligands to $\mathrm{Kv} 2.1$, it requires crosslinking a labeled $\sigma-\mathrm{R}$ ligand to Kv2.1 or ligand binding assay using purified functional Kv2.1 protein, which warrants future investigations.

$\mathrm{Kv} 2.1$ is a delayed rectifier-type potassium channel with diverse functions, including regulations of neuronal excitability and transmitter release, insulin secretion, and heart rate [35]. Because of a pro-apoptotic role in neurons and beta cells [23], Kv2.1 has recently become an attractive anti-neurodegenerative and anti-diabetic target [24]. While various agents have been found to inhibit Kv2.1 activity, reports of high-affinity small molecule Kv2.1 inhibitors remain scarce [24], hampering Kv2.1-modulatory therapeutic development. In this regard, our finding of novel potent Kv2.1 inhibitors is of timely importance. There has not been a reported pharmacophore of Kv2.1 inhibitors. The chemical structures of the known Kv2.1 inhibitor compounds vary drastically; e.g., donepezil, galantamine, RY796, and isoliquiritigenin [24]. It is intriguing that donepezil has been used as both a Kv2.1 inhibitor [23] and a $\sigma 1-\mathrm{R}$ ligand [9]. As any ligand would bind off-targets at high concentrations, Kv2.1 may represent an off-target for $\sigma-\mathrm{R}$ ligands. Since a structurally similar subgroup of $\sigma-\mathrm{R}$ ligand, but not all of them, inhibited Kv2.1 to various extent we speculate that there is a direct interaction between sigma ligands and Kv2.1 protein. It is interesting to note the similarity between the structures of PB28 and CM777, the two most potent Kv2.1-inhibitory $\sigma-\mathrm{R}$ ligands characterized herein (Figure 4B). While each is composed of two ring structures connected by an alkyl chain, both contain a piperazine group. Significantly, if the cyclohexylpiperazine group is substituted by an isoquinolin group (in CM398), the Kv2.1 inhibitory function is abolished. The structures of other three Kv2.1inhibiting $\sigma-\mathrm{R}$ ligands (BD1047, NE100, and SM21) differ substantially from CM777 and PB28 (Figure 4B), and their inhibitory potency is $\sim 10$ fold lower with an estimated IC50 at $\sim 50 \mu \mathrm{M}$. Therefore, the structureand-function information obtained here is useful for future development of more Kv2.1-selective therapeutic inhibitors. Given the fact that hundreds of compounds have been found to bind $\sigma$-Rs with some in clinical use or trials [9], $\sigma-\mathrm{R}$ ligands constitute a rich repertoire for discovering novel Kv2.1 inhibitors.

Another interesting observation is the inhibitory effect of PB28 on photoreceptor electrophysiology measured by ERG. Compared to studies in the brain and other tissues, Kv2.1 is much less investigated in the retina (total 8-10 PubMed publications). The exceptionally high expression of Kv2.1 in mouse photoreceptor inner segments implicates functional importance. However, in photoreceptors Kv2.1 co-assembles with Kv8.2 channel to mediate $\mathrm{K}^{+}$efflux, and may thus facilitate strong hyperpolarization of photoreceptors [22]. This is also evidenced by the fact that the co-assembled channel generates unique biophysical characteristics identical to photoreceptor $I_{\mathrm{K}}$ [36]. In our in vitro study, inhibition of the Kv2.1 channel by $\sigma-\mathrm{R}$ ligands did not alter channel voltage-dependent activation or kinetics, hence we infer that these agents probably directly inhibit the function of a Kv2.1/Kv8.2 hetero-multimeric channel. Our mouse ERG recording showed severely reduced a-wave and also b-wave responses following intravitreal injection of PB28. This is consistent with the contribution of Kv2.1 channel to ERG a-waves due to the hyperpolarization of photoreceptors.

While a protective role of $\sigma 1-\mathrm{R}$ for retinal neurons has been strongly advocated by a number of genetic and pharmacological studies $[6,7]$, its influence on phototransduction remains underexplored [7, 32]. The role of $\sigma 2-\mathrm{R}$ in the retina is not known. Here we found that compared to WT mice, PB28 inhibition of ERG a-waves were attenuated to some degree due to $\sigma 1-\mathrm{R}$ knockout, suggesting a specific role of $\sigma 1 \mathrm{R}$ in retinal photoresponse. This is not surprising in light of the reported $\sigma 1-\mathrm{R}$ interactions with various channels that are also present in retinal photoreceptors and secondary neurons [20]. Interestingly, a good portion of PB28 inhibition of ERG (especially b-waves) persisted in $\sigma 1-\mathrm{R} \mathrm{KO}$ mice, indicating a non- $\sigma 1-\mathrm{R}$ effect. Although we cannot identify which targets were responsible for this effect, Kv2.1 may have at least partially mediated the PB28-induced ERG inhibition considering the great abundance of Kv2.1 in photoreceptors and potent PB28 inhibition of Kv2.1 activity measured in vitro. Future experiments using PB28 
combined with guangitoxin-1E, a known Kv2.1 inhibitor, would help answer this question.

\section{MATERIALS AND METHODS}

\section{Cell line and reagents}

Human HEK293 cells were purchased from American Type Culture Collection (ATCC, Manassas, VA). HEK293 cells with stable expression on Kv2.1 channel was obtained from Durga Mohapatra. Cells were maintained in a complete growth medium (DMEM high glucose $+10 \%$ heat inactivated Fetal Bovine Serum $+1 \mathrm{X}$ Penicillin and Streptomycin + 1X Glutamax all from Lifetechnology, USA). For selection of Kv2.1 stable cells, $400 \mu \mathrm{g} / \mathrm{ml}$ of G418 was used. Cells were cultured up to $70-90 \%$ confluency in a $5 \% \mathrm{CO}_{2}$ incubator at $37^{\circ} \mathrm{C}$ and $95 \%$ humidity. Cells were regularly sub-cultured to avoid over confluency.

Reagents: Puromycin dihydrochloride, Pre084 hydrochloride, BD1047 dihydrobromide, and NE100 were purchased from Tocris. PB28 was from Sigma-Aldrich. CM398 and CM777 were synthesized by Dr. McCurdy's laboratory [3]. All other reagents were purchased from Sigma-Aldrich or Thermo-Fisher unless specifically stated.

\section{Knockout of $\sigma 1-R$ using the CRISPR/Cas9 genome editing technology}

To generate a $\sigma 1-\mathrm{R}$ knockout HEK293 human cell line, a CRISPR/Cas9 genome-editing approach was used, as described in our previous report with minor modifications [3]. Briefly, three CRISPR guide RNAs (gRNAs) targeting the human $\sigma 1-\mathrm{R}$ gene (SIGMAR1) were chosen. Targeted sequences are 5'-GGCCTTCTCTCGTCTGATCG-3', 5'-TGACCCA GGTCGTCTGGCTC-3', and 5'-GTGGGCCGTGGGCCG GCGGT-3'. Cloning of gRNAs into lentiCRISPR v2 and lentivirus production were performed as reported [38]. The cells were transduced with lentivirus for 3 days, and genome-edited cells were selected with $1 \mu \mathrm{g} / \mathrm{ml}$ puromycin for 1 week, and $\sigma 1-\mathrm{R} \mathrm{KO}$ was then verified by Western blotting.

\section{Western blotting to confirm $\sigma 1-R$ knockout}

Following CRISPR/Cas9 genome-editing, selected HEK293 cells were collected and cell lysates were solubilized in RIPA buffer. Proteins were separated on a 4-20\% Mini-PROTEAN TGX precast gel (Bio-Rad, Hercules, CA) and transferred to a PVDF membrane. A blot was incubated with a primary antibody: rabbit anti- $\sigma 1-R$ (Santa Cruz Biotechnology, Dallas, TX, 1:200), mouse monoclonal anti-Kv2.1 (Clone K89/34, NeuroMab, CA, 1:1000), or mouse anti- $\beta$-actin (SigmaAldrich, USA, 1:10000), washed 3 times, and then incubated with an HRP-conjugated secondary antibody (goat anti-rabbit or mouse, Bio-Rad, 1:5000). Specific protein bands on the blot were visualized by applying enhanced chemiluminescence reagents (Pierce, Rockford, IL) and then recorded with a LAS-4000 Mini imager (GE, Piscataway, NJ).

\section{Animals}

All animal procedures conform to the NIH Guide for the Care and Use of Laboratory Animals. Animal protocols (M02102/M05434) were approved by the Institutional Animal Care and Use Committee at the University of Wisconsin-Madison. Heterozygous $\sigma 1-\mathrm{R}$ knockout mice, namely Oprs 1 mutant (+/-) B6;129S5Sigmar1Gt(OST422756) Lex/Mmucd mouse litters on a C57BL/6J $\times 129 \mathrm{~s} / \mathrm{SvEv}$ mixed background, were purchased from the Mutant Mouse Regional Resource Center (\#011750, MMRRC, UC Davis, CA, USA). The colony of homozygous $\sigma 1-\mathrm{R} \mathrm{KO}$ mice was then established by backcrossing to $\mathrm{C} 57 \mathrm{BL} / 6 \mathrm{~J}$ mice for $>7$ generations [39]. Litter mates with homozygous alleles of the sigma-1 receptor gene (Sigmar 1) were used as wild type control. $\sigma 1-\mathrm{R}$ WT and $\sigma 1-\mathrm{R} \mathrm{KO}$ litter mates were genotyped as previously reported [25] before the use for experiments. Animals were maintained on a $4 \%$ fat diet (8604 M/R, Harkland Teklad, Madison, WI) and subjected to standard light cycles $(12 \mathrm{~h} / 12 \mathrm{~h}$ light/dark). Both male and female mice in the age range of postnatal days 40-50 were used in experiments. Animals were euthanized in a chamber gradually filled with $\mathrm{CO}_{2}$.

\section{Immunohistochemistry for detection of Kv2.1 and $\sigma 1-R$ on retinal sections}

Mice were euthanized by $\mathrm{CO}_{2}$ asphyxiation followed by cervical dislocation. Retinal cryosections were prepared according to our published methods [31, 40]. Briefly, eyeballs were fixed overnight in $4 \%$ paraformaldehyde at $4{ }^{\circ} \mathrm{C}$ and then soaked in $30 \%$ sucrose (in PBS) overnight at $4{ }^{\circ} \mathrm{C}$, and $10 \mu \mathrm{m}$ sections were cut from the eyeballs frozen in the optimum cutting temperature (OCT) embedding medium.

Immunostaining was performed on retinal cryosections following our previously described method [41] with minor modifications. Briefly, retinal sections were permeabilized with $0.1 \%$ Triton X-100 in PBS for 20 min, blocked with 5\% normal donkey serum (Jackson Immunoresearch Lab, MS) for $1 \mathrm{~h}$ at room temperature, and then incubated with a primary antibody overnight at $4{ }^{\circ} \mathrm{C}$. Sources of primary antibodies are the following: rabbit anti- $\sigma 1-\mathrm{R}$ serum (in-house produced, 1:700) [25]; Mouse monoclonal anti-Kv2.1 (Clone K89/34, NeuroMab, CA, 1:300) [25]. After rinsing the section $3 \times$, a secondary antibody (Alexa-488 conjugated donkey-anti-rabbit or Alexa-555-conjugated goat-anti-mouse) at $1 \mu \mathrm{g} / \mathrm{ml}$ was applied at room temperature for $1 \mathrm{~h}$. Sections were then rinsed and counterstained with DAPI and cover-slipped. Fluorescence images were acquired under a $60 \times$ oil 
objective lens with a Nikon A1RS confocal microscope (Nikon Inc, Mellville, NY).

\section{Electrophysiology}

Kv2.1 channel currents were recorded by wholecell patch clamp at room temperature using an Axopatch 200B amplifier (Molecular Devices, Sunnyvale, CA) and the Digidata 1440A data acquisition system (Molecular Devices, Sunnyvale, CA). The data were low-pass filtered at $1 \mathrm{kHz}$, and digitized at $0.5 \mathrm{kHz}$. The cell-covered glass coverslips were placed at the bottom of a $13 \mathrm{~mm}$ chamber (Warner Instruments, MA) mounted on the fixed stage of a Nikon FN-1 microscope and continuously perfused using the HEPES Ringer's (HR) buffer containing (in mM): 135 $\mathrm{NaCl}, 5 \mathrm{KCl}, 10$ HEPES, 10 glucose, $1.8 \mathrm{CaCl}_{2}$, and 1 $\mathrm{MgCl}_{2}$. The $\mathrm{pH}$ was adjusted to 7.4 using $\mathrm{NaOH}$.

Patch pipettes were made from borosilicate glass (BF150-117-10, Sutter Instruments, Novato, CA) using a horizontal pipette puller (P-1000, Sutter Instruments, Novato, CA) and fire polished (MF-830, Narishige, Tokyo, Japan). The recording electrodes, when filled with (in $\mathrm{mM}$ ) $30 \mathrm{KCl}, 83 \mathrm{~K}$-gluconate, 10 HEPES, 5.5 EGTA, $0.5 \mathrm{CaCl}_{2}, 4 \mathrm{Mg}$-ATP, and $0.1 \mathrm{GTP}$, and adjusted to $\mathrm{pH} 7.2$ using $\mathrm{KOH}$, measured a tip resistance between 3.5-4.5 M $\Omega$. Whole cell capacitance and series resistance were monitored and compensated throughout the recording. Gravity perfusion system was used for HR perfusion and sigma receptor ligand application. The $\mathrm{Kv} 2.1$ current was monitored either using a linear voltage ramp from $-50 \mathrm{mV}$ to $+50 \mathrm{mV}$ or a voltage step series between $-50 \mathrm{mV}$ to $+50 \mathrm{mV}$. In between recordings, the cell was held at $-60 \mathrm{mV}$. All recordings were performed at room temperature. We used $1^{\text {st }}$ order exponential nonlinear curve fitting equation; for the time course data

$$
y=A 1 * \exp \left(-\frac{x}{t 1}\right)+y 0
$$

to determine inhibition time constant in Origin (Origin Lab, Northampton, MA). Whole cell data was acquired and analyzed using pClamp10 and all plots were generated in Origin. Conductance was measured from the current amplitude divided by $\mathrm{K}^{+}$ion driving force; $G=I /$ $(V m-E k)$ where $G$ is conductance, $I$ is current, $V m$ is membrane potential, and $E k$ is Nernst potential for $\mathrm{K}^{+}$. When normalized with the maximal conductance (G/ $\left.\mathrm{G}_{\max }\right)$, the curves were fit with a Boltzmann nonlinear curve fit; half maximal voltage dependence is $V 0.5$ and slope is $S$.

$$
G=G \min +\frac{(G m a x-G m i n)}{1+\exp ((V 0.5-V m) / S)}
$$

\section{Electroretinogram}

The animal procedures were in compliance with the ARVO Statement for the Use of Animals in Ophthalmic and Vision Research. Details of ERG recording were described in our recent report [40]. Briefly, 40-day old $\sigma 1-\mathrm{R}$ WT and $\sigma 1-\mathrm{R} \mathrm{KO}$ mice were anesthetized with ketamine/xylazine ( 80 and $10 \mathrm{mg} / \mathrm{kg}$ IP). Mice were dark-adapted overnight and ERG measurements were performed using standard ISEVC protocol using a HmsERG system (Ocuscience, NV) the next day. ERG data were analyzed using ERGView and plotted in Origin.

\section{Intravitreal injection of PB28}

Intravitreal injection was performed as we previously reported [42, 43]. Mice were anesthetized with the ketamine/xylazine $(80 / 10 \mathrm{mg} / \mathrm{kg}$ IP) cocktail. Proparacaine hydrochloride $(0.5 \%$; Alcon Laboratories, Inc., Fort Worth, TX) and ofloxacin ophthalmic solution (0.3\%; Allergan Inc., Irvine, CA) were applied to the ocular surface before injection for topical anesthesia and infection prevention, respectively. To avoid injuries to the lens, a $\sim 0.5 \mathrm{~mm}$ incision posterior to the temporal limbus was first made using a 27-gauge single-use needle (BD, Franklin Lakes, $\mathrm{NJ})$, and then a 30 -gauge blunt-end needle (10 mm length; Hamilton, Reno, NV) in a Hamilton 701RN syringe was inserted through the incision. The needle was advanced approximately $1.5 \mathrm{~mm}$ deep while avoiding the lens, angled toward the optic nerve until the needle tip was seen in the center of the vitreous; then, $2 \mu \mathrm{l}$ of solution was injected. PBS control (containing equivalent amount of DMSO) was injected to the left eye and PB28 in PBS $(20 \mu \mathrm{M})$ was injected to the right eye. To ensure that no infection would occur, bacitracin ophthalmic ointment (E. Fougera \& Co., Melville, NY) was applied immediately after pulling out the needle. Injections were performed using a UMP3 ultra micro-injection system (World Precision Instruments, Sarasota, FL)

\section{Statistical analysis}

All experiments were performed at least five times. Data was analyzed for significance using Student t-test. Data was interpreted as significant when $p$ value measured less than 0.05 .

\section{CONCLUSIONS}

Using a human cell line specifically overexpressing Kv2.1 and with $\sigma 1 \mathrm{R}$ depleted via genome editing, we identified an $\sigma$-R-independent Kv2.1-inhibitory function of a defined group of ligands that were previously characterized as $\sigma$-R-selective. The significance of our finding can be several fold. First, these $\sigma$-R ligands may represent a novel set of sought-after Kv2.1 inhibitors, with PB28 and CM777 being the most 
potent. Second, comparison among PB28 and CM777 (Kv2.1 inhibitory) and CM398 (Kv2.1 non-inhibitory) confers new knowledge of structure-activity relationship highlighting the importance of the piperazine group. Third, as the $\sigma 2-\mathrm{R}$ gene sequence is not known [3], $\sigma 2-\mathrm{R}$ ligands provide the only approach for $\sigma 2-\mathrm{R}$ targeted imaging and therapeutic investigations [37]. Our findings here recommend considerations of possible off-targets of $\sigma 2-\mathrm{R}$ ligands. Moreover, $\sigma 1-\mathrm{R}$ and $\sigma 2-\mathrm{R}$ are considered as potential targets for treating a variety disorders, including addiction and psychotic disorders, neurodegenerative diseases, pain, and cancers [9]. $\mathrm{Kv} 2.1$ inhibition has been proposed as an approach to treat neurodegenerative (e.g. Alzheimer's) and diabetic diseases [24]. Thus, optimal therapeutic outcomes may be attainable by conciliating drug effects on $\sigma$-Rs and the Kv2.1 channel. All these perspectives warrant continued research to open new avenues to advance Kv2.1 and/or $\sigma$-R-targeted therapeutic development.

\section{Author contributions}

Conception and design (LWG, BRP), data collection (XL, YF, HY, TM, JL), Data analysis and interpretation (XL, YF, HY, TM, JL, LWG, BRP), drafting of manuscript (XL, YF, LWG, BRP), critical revision (CRM, LWG, BRP), and all authors approved final version to be published.

\section{ACKNOWLEDGMENTS}

The authors thank Dr. Durga Mohapatra for providing Kv2.1 constructs and HEK-Kv2.1 stable cells. We also thank Dr. Arnold Ruoho and Dr. Meyer Jackson for informative discussions.

\section{CONFLICTS OF INTEREST}

None.

\section{FUNDING}

This work is supported by the National Institute of Health grants; EY024995 (BRP), EY022678 (L-WG), DA023205(CRM), and EY016665 (to the University of Wisconsin Vision Core); the Retina Research Foundation M. D. Matthews Research Professorship (to BRP), Morgridge Institute for Research \& the James Christenson Estate Macular Degeneration Research Award (to L-WG). Grant support also received from the Shanghai Key Laboratory of Psychotic Disorders (13dz2260500), Shanghai Health Talent Professional Project (XYQ2013114), Shanghai Municipal Commission of Health and Family Planning (20124106) and the National Natural Science Foundation of China (81371491) to YFu.

\section{REFERENCES}

1. Quirion R, Bowen WD, Itzhak Y, Junien JL, Musacchio JM, Rothman RB, Su TP, Tam SW, Taylor DP. A proposal for the classification of sigma binding sites. Trends Pharmacol Sci. 1992; 13: 85-6.

2. Hayashi T, Su TP. Sigma-1 receptor chaperones at the ER-mitochondrion interface regulate $\mathrm{Ca}(2+)$ signaling and cell survival. Cell. 2007; 131: 596-610. https://doi. org/10.16/j.cell.2007.08.036.

3. Chu UB, Mavlyutov TA, Chu ML, Yang H, Schulman A, Mesangeau C, McCurdy CR, Guo LW, Ruoho AE. The sigma-2 receptor and progesterone receptor membrane component 1 are different binding sites derived from independent genes. EBioMedicine. 2015; 2: 1806-13. https://doi.org/10.1016/j.ebiom.2015.10.017.

4. Su TP, Hayashi T, Maurice T, Buch S, Ruoho AE. The sigma-1 receptor chaperone as an inter-organelle signaling modulator. Trends Pharmacol Sci. 2010; 31: 557-66. https:// doi.org/10.16/j.tips.2010.08.007.

5. Nguyen L, Lucke-Wold BP, Mookerjee SA, Cavendish JZ, Robson MJ, Scandinaro AL, Matsumoto RR. Role of sigma-1 receptors in neurodegenerative diseases. J Pharmacol Sci. 2015; 127: 17-29. https://doi.org/10.1016/j. jphs.2014.12.005.

6. Mavlyutov TA, Guo LW. Peeking into sigma-1 receptor functions through the retina. Adv Exp Med Biol. 2017; 964: 285-97. https://doi.org/10.1007/978-3-319-50174-1_19.

7. Wang J, Saul A, Roon P, Smith SB. Activation of the molecular chaperone, sigma 1 receptor, preserves cone function in a murine model of inherited retinal degeneration. Proc Natl Acad Sci U S A. 2016; 113: E3764-72. https://doi. org/10.1073/pnas.1521749113.

8. Su TP, Su TC, Nakamura Y, Tsai SY. The Sigma-1 receptor as a pluripotent modulator in living systems. Trends Pharmacol Sci. 2016; 37: 262-78. https://doi.org/10.1016/j. tips.2016.01.003.

9. Matsumoto RR, Nguyen L, Kaushal N, Robson MJ. Sigma (sigma) receptors as potential therapeutic targets to mitigate psychostimulant effects. Adv Pharmacol. 2014; 69: 323-86. https://doi.org/10.1016/B978-0-12-420118-7.00009-3.

10. Brent PJ, Pang G, Little G, Dosen PJ, Van Helden DF. The sigma receptor ligand, reduced haloperidol, induces apoptosis and increases intracellular-free calcium levels $[\mathrm{Ca} 2+] \mathrm{i}$ in colon and mammary adenocarcinoma cells. Biochem Biophys Res Commun. 1996; 219: 219-26.

11. Brent PJ, Saunders H, Dunkley PR. Intrasynaptosomal free calcium levels in rat forebrain synaptosomes: modulation by sigma (sigma) receptor ligands. Neurosci Lett. 1996; 211: 138-42.

12. Vilner BJ, Bowen WD. Modulation of cellular calcium by sigma-2 receptors: release from intracellular stores in human SK-N-SH neuroblastoma cells. J Pharmacol Exp Ther. 2000; 292: 900-11. 
13. Tchedre KT, Huang RQ, Dibas A, Krishnamoorthy RR, Dillon GH, Yorio T. Sigma-1 receptor regulation of voltagegated calcium channels involves a direct interaction. Invest Ophthalmol Vis Sci. 2008; 49: 4993-5002. https://doi. org/10.1167/iovs.08-1867.

14. Cheng ZX, Lan DM, Wu PY, Zhu YH, Dong Y, Ma L, Zheng P. Neurosteroid dehydroepiandrosterone sulphate inhibits persistent sodium currents in rat medial prefrontal cortex via activation of sigma-1 receptors. Exp Neurol. 2008; 210: 128-36. https://doi.org/10.1016/j. expneurol.2007.10.004.

15. Zhang H, Katnik C, Cuevas J. Sigma receptor activation inhibits voltage-gated sodium channels in rat intracardiac ganglion neurons. Int J Physiol Pathophysiol Pharmacol. 2009; 2: 1-11.

16. Johannessen M, Fontanilla D, Mavlyutov T, Ruoho AE, Jackson MB. Antagonist action of progesterone at sigmareceptors in the modulation of voltage-gated sodium channels. Am J Physiol Cell Physiol. 2011; 300: C328-37. https://doi.org/10.1152/ajpcell.00383.2010.

17. Hayashi $\mathrm{T}$, Maurice $\mathrm{T}, \mathrm{Su}$ TP. $\mathrm{Ca}(2+)$ signaling via sigma(1)-receptors: novel regulatory mechanism affecting intracellular $\mathrm{Ca}(2+)$ concentration. J Pharmacol Exp Ther. 2000; 293: 788-98.

18. Aydar E, Palmer CP, Klyachko VA, Jackson MB. The sigma receptor as a ligand-regulated auxiliary potassium channel subunit. Neuron. 2002; 34: 399-410.

19. Kinoshita M, Matsuoka Y, Suzuki T, Mirrielees J, Yang J. Sigma-1 receptor alters the kinetics of Kv1.3 voltage gated potassium channels but not the sensitivity to receptor ligands. Brain Res. 2012; 1452: 1-9. https://doi. org/10.1016/j.brainres.2012.02.070.

20. Kourrich S, Su TP, Fujimoto M, Bonci A. The sigma-1 receptor: roles in neuronal plasticity and disease.Trends Neurosci. 2012; 35: 762-71. https://doi.org/10.1016/j. tins.2012.09.007.

21. Kourrich S, Hayashi T, Chuang JY, Tsai SY, Su TP, Bonci A. Dynamic interaction between sigma-1 receptor and Kv1.2 shapes neuronal and behavioral responses to cocaine. Cell. 2013; 152: 236-47. https://doi.org/10.1016/j. cell.2012.12.004.

22. Holter P, Kunst S, Wolloscheck T, Kelleher DK, Sticht C, Wolfrum U, Spessert R. The retinal clock drives the expression of Kcnv2, a channel essential for visual function and cone survival. Invest Ophthalmol Vis Sci. 2012; 53: 6947-54. https://doi.org/10.1167/iovs.12-10234.

23. Yuan H, Wang WP, Feng N, Wang L, Wang XL. Donepezil attenuated oxygen-glucose deprivation insult by blocking Kv2.1 potassium channels. Eur J Pharmacol. 2011; 657: 76-83. https://doi.org/10.1016/j.ejphar.2011.01.054.

24. Zhou TT, Quan LL, Chen LP, Du T, Sun KX, Zhang JC, Yu L, Li Y, Wan P, Chen LL, Jiang BH, Hu LH, Chen J, et al. SP6616 as a new Kv2.1 channel inhibitor efficiently promotes beta-cell survival involving both $\mathrm{PKC} /$ Erk1/2 and
CaM/PI3K/Akt signaling pathways. Cell Death Dis. 2016; 7: e2216. https://doi.org/10.1038/cddis.2016.119.

25. Mavlyutov TA, Epstein ML, Verbny YI, Huerta MS, Zaitoun I, Ziskind-Conhaim L, Ruoho AE. Lack of sigma-1 receptor exacerbates ALS progression in mice. Neuroscience. 2013; 240: 129-34. https://doi.org/10.1016/j. neuroscience.2013.02.035.

26. O'Connell KM, Loftus R, Tamkun MM. Localizationdependent activity of the Kv2.1 delayed-rectifier $\mathrm{K}+$ channel. Proc Natl Acad Sci U S A. 2010; 107: 12351-6. https://doi.org/10.1073/pnas.1003028107.

27. Maurice T, Su TP. The pharmacology of sigma-1 receptors. Pharmacol Ther. 2009; 124: 195-206. https://doi.org/10.16/j. pharmthera.2009.07.001.

28. Azzariti A, Colabufo NA, Berardi F, Porcelli L, Niso M, Simone GM, Perrone R, Paradiso A. Cyclohexylpiperazine derivative PB28, a sigma2 agonist and sigma1 antagonist receptor, inhibits cell growth, modulates P-glycoprotein, and synergizes with anthracyclines in breast cancer. Mol Cancer Ther. 2006; 5: 1807-16. https://doi.org/10.1158/1535-7163. MCT-05-0402.

29. Abate C, Elenewski J, Niso M, Berardi F, Colabufo NA, Azzariti A, Perrone R, Glennon RA. Interaction of the sigma(2) receptor ligand PB28 with the human nucleosome: computational and experimental probes of interaction with the H2A/H2B dimer. ChemMedChem. 2010; 5: 268-73. https://doi.org/10.1002/cmdc.200900402.

30. Klumpp DJ, Song EJ, Pinto LH. Identification and localization of $\mathrm{K}+$ channels in the mouse retina. Vis Neurosci. 1995; 12: 1177-90.

31. Mavlyutov TA, Nickells RW, Guo LW. Accelerated retinal ganglion cell death in mice deficient in the Sigma-1 receptor. Mol Vis. 2011; 17: 1034-43.

32. Ha Y, Saul A, Tawfik A, Williams C, Bollinger K, Smith R, Tachikawa M, Zorrilla E, Ganapathy V, Smith SB. Late-onset inner retinal dysfunction in mice lacking sigma receptor 1 (sigmaR1). Invest Ophthalmol Vis Sci. 2011; 52: 7749-60. https://doi.org/10.1167/iovs.11-8169.

33. Thomas P, Smart TG. HEK293 cell line: a vehicle for the expression of recombinant proteins. J Pharmacol Toxicol Methods. 2005; 51: 187-200. https://doi.org/10.1016/j. vascn.2004.08.014.

34. He YL, Zhang CL, Gao XF, Yao JJ, Hu CL, Mei YA. Cyproheptadine enhances the $\mathrm{I}(\mathrm{K})$ of mouse cortical neurons through sigma-1 receptor-mediated intracellular signal pathway. PLoS One. 2012; 7: e41303. https://doi. org/10.1371/journal.pone.0041303.

35. Wulff H, Castle NA, Pardo LA. Voltage-gated potassium channels as therapeutic targets. Nat Rev Drug Discov. 2009; 8: 982-1001. https://doi.org/10.1038/nrd2983.

36. Czirjak G, Toth ZE, Enyedi P. Characterization of the heteromeric potassium channel formed by kv2.1 and the retinal subunit kv8.2 in Xenopus oocytes. J Neurophysiol. 2007; 98: 1213-22. https://doi.org/10.1152/jn.00493.2007. 
37. Xu J, Zeng C, Chu W, Pan F, Rothfuss JM, Zhang F, Tu Z, Zhou D, Zeng D, Vangveravong S, Johnston F, Spitzer $\mathrm{D}$, Chang $\mathrm{KC}$, et al. Identification of the PGRMC1 protein complex as the putative sigma-2 receptor binding site. Nature communications. 2011; 2: 380. https://doi. org/10.1038/ncomms1386.

38. Sanjana NE, Shalem O, Zhang F. Improved vectors and genome-wide libraries for CRISPR screening. Nat Methods. 2014; 11: 783-4. https://doi.org/10.1038/nmeth.3047.

39. Fontanilla D, Johannessen M, Hajipour AR, Cozzi NV, Jackson MB, Ruoho AE. The hallucinogen N,Ndimethyltryptamine (DMT) is an endogenous sigma-1 receptor regulator. Science. 2009; 323: 934-7. https://doi. org/10.1126/science.1166127.

40. Zhao L, Li J, Fu Y, Zhang M, Wang B, Ouellette J, Shahi PK, Pattnaik BR, Watters JJ, Wong WT, Guo LW. Photoreceptor protection via blockade of BET epigenetic readers in a murine model of inherited retinal degeneration. J Neuroinflammation. 2017; 14: 14. https://doi.org/10.1186/ s12974-016-0775-4.
41. Mavlyutov TA, Epstein M, Guo LW. Subcellular localization of the sigma-1 receptor in retinal neurons - an electron microscopy study. Sci Rep. 2015; 5: 10689. https:// doi.org/10.1038/srep10689.

42. Zhao L, Chen G, Li J, Fu Y, Mavlyutov TA, Yao A, Nickells RW, Gong S, Guo LW. An intraocular drug delivery system using targeted nanocarriers attenuates retinal ganglion cell degeneration. J Control Release. 2017; 247: 153-66. https:// doi.org/10.1016/j.jconrel.2016.12.038.

43. Li J, Zhao L, Urabe G, Fu Y, Guo LW. Epigenetic intervention with a BET inhibitor ameliorates acute retinal ganglion cell death in mice. Mol Vis. 2017; 23: 149-59.

44. Su TP, Wu XZ, Cone EJ, Shukla K, Gund TM, Dodge AL, Parish DW. Sigma compounds derived from phencyclidine: identification of PRE-084, a new, selective sigma ligand. J Pharmacol Exp Ther. 1991; 259: 543-50.

45. Mach RH, Wu L, West T, Whirrett BR, Childers SR. The analgesic tropane analogue (+/-)-SM 21 has a high affinity for sigma2 receptors. Life Sci. 1999; 64: PL131-7. 